Portland State University

PDXScholar

\title{
Trauma-informed Care as a Service Approach for Youth Experiencing Houselessness: a Scoping Review of the Literature
}

Crystal Wink

Portland State University

Follow this and additional works at: https://pdxscholar.library.pdx.edu/honorstheses

Part of the Social Work Commons

Let us know how access to this document benefits you.

\section{Recommended Citation}

Wink, Crystal, "Trauma-informed Care as a Service Approach for Youth Experiencing Houselessness: a Scoping Review of the Literature" (2020). University Honors Theses. Paper 826.

https://doi.org/10.15760/honors.845

This Thesis is brought to you for free and open access. It has been accepted for inclusion in University Honors Theses by an authorized administrator of PDXScholar. Please contact us if we can make this document more accessible: pdxscholar@pdx.edu. 
Trauma-informed Care as a Service Approach for

Youth Experiencing Houselessness: A Scoping Review of the Literature

Crystal Wink

Portland State University

Thesis Advisors

Stephanie Bryson

Mollie Janssen 


\section{Abstract}

The purpose of this systematic scoping review was to find what the current literature includes regarding the topic of Trauma-informed Care (TIC) as a service approach to serve youth who are experiencing houselessness. The review was guided by the research question, 'How might Trauma-informed Care be practiced within houseless youth organizations?' A comprehensive search of the databases PsycINFO and Academic Search Premier, as well as the grey literature database, Bielefeld Academic Search Engine (BASE) were performed to locate articles and readings relevant to the topic. To further increase the breadth of the scope, publications were located and selected from a nationally recognized trauma-informed organization, the Substance Abuse and Mental Health Administration (SAMHSA), and a statewide trauma-informed organization, Trauma Informed Oregon (TIO). A de-duplication and screening process was applied to all readings, leaving eligible full-text articles to be reviewed. During the review, key concepts and definitions were identified in order to come to a fuller understanding of the scope of the topic, including where gaps exist in the research. Thematic analysis was carried out on the remaining full-text articles to extract common themes. The search process was charted in a PRISMA flow diagram, while the results were reported by narrative description.

\section{Keywords: Trauma-informed Care, houseless youth, houselessness}


Trauma-informed Care as a Service Approach for Youth Experiencing Houselessness: A Scoping Review of the Literature

\section{Introduction}

It is estimated that anywhere from 1 to 1.7 million youth are houseless in the United States each year (Davies \& Allen, 2017). It is likely that this number is higher as houseless youth are a difficult community to engage (Davies \& Allen, 2017). In this review, houseless youth are defined as people from ages 14-25 who are living without secure permanent housing (e.g. couch surfing, staying in a Making the engagement stage vehicle or shelter, or living on the street). challenging are houseless youths' backgrounds that often include a history of family violence, child maltreatment, and family separations, which cause them to be distrusting and often fearful of adults (Mohr, Coates, \& Mcleod, 2012). Youths' negative associations of adults is one cause for their apprehension in receiving services from adults in helping roles. Despite youth's reluctance, the engagement process between houseless youth and helping professionals can serve as a valuable resource to assist youth in exiting their houseless situation (Steele \& Malchiodi, 2012).

A common misperception of houseless youth is that they are defiant, choose to be houseless to avoid following rules, and can easily return home. This notion completely fails to recognize the traumatic experiences that lie at the center of many young people's houseless experiences (Mohr, Coates, \& Mcleod, 2012). A large number of houseless youth are fleeing from severe, negative conditions within their family systems or communities (Davies \& Allen, 2017). Many of these young people have been victims and witnesses of domestic violence, sexually or physically abused, a child of a parent who abuses substances, or exposed to some 
type of neighborhood or community violence (Davies \& Allen, 2017). A study that consisted of 329 participants, found that " $48 \%$ of houseless youth come from families that had some kind of intra-familial abuse. The average abused youth had more than one abuser and first was abused at younger than four years old" (Davies \& Allen, 2017). Child maltreatment as well as trauma and violence are strong precursors to youth houselessness for many young people (Vitopoulos, Keilburger, Frederick, \& Mckenzie, 2017).

A study conducted on houseless youth in Canada found that out of the "100 youth interviewed, on average, male and female participants both reported having 11 or 12 different forms of highly stressful events before and after becoming houseless" (Mohr, Coates, \& Mcleod, 2012). It is suggested that not only are youth coming from traumatic backgrounds, but the very nature of houselessness itself is traumatic (Lambert, Emerson, Horan, \& Naughton, 2017). One study reported that $85 \%$ of houseless youth witnessed someone being physically assaulted on the streets, $69 \%$ saw someone being seriously injured while being attacked, $31 \%$ had been a witness of murder, and $24 \%$ had witnessed sexual assault (Davies \& Allen, 2017). The high rates of violence and abuse many young houseless individuals are exposed to suggests the necessity for houseless youth agencies and helping professionals to have an understanding and knowledge of trauma, how it negatively impacts the youth they serve, and how services might best be delivered without causing further harm (Davies \& Allen, 2017).

Attachment theorists suggest that enduring early adverse experiences with adults on whom youth are supposed to be able to rely fractures their ability to establish and foster healthy relationships with other people later (Levenson, 2017). This becomes a barrier for youth to exit houselessness as positive relationships, especially those with safe helping professionals, are extremely important in allowing them to get their immediate and long-term needs met (Steele \& 
Malchiodi, 2012). The helping relationship may serve as a model for youth to develop and maintain further positive relationships based on mutuality and respect (Steele \& Malchiodi, 2012).

Trauma-informed Care (TIC) is a service approach that is gaining increasing attention among various fields for its applicability to houseless youth as it serves as a guide for service users and providers to develop and maintain a healthy, professional "Trauma-informed Care is a strengths-based framework that is grounded in an understanding of and responsiveness to the impact of trauma, that relationship. (Levenson, emphasizes physical, psychological, and emotional safety for both providers and survivors and that 2017). Helping professionals who creates opportunities for survivors to rebuild a sense of control and empowerment." (Mohr, Coates, \& provide trauma-informed care to Mcleod, 2012)

clients do so from a place of

recognition and understanding of how past trauma affects current behavior (Levenson, 2017). Through a trauma-informed lens, client behaviors that are typically considered "difficult," may be perceived as coping strategies that assist youth in surviving (Clark, Classen, Fourt, \& Shetty, 2015). It is suggested that to a young trauma survivor, service settings such as day centers where houseless youth get their basic needs met, can be psychologically triggering as they so often consist of noisy, overstimulating environments (SAMHSA, 2014). At times these establishments may even unintentionally serve as platforms for conflict that erupts between service users, which may be triggering for youth who have experienced or been exposed to various types of violence.

Trauma-informed Care is practiced at the organizational level, which means that an entire houseless youth organization is guided by the core principles of TIC (SAMHSA, 2014). There are several variations of the principles that guide Trauma-informed Care depending on which population the approach is serving, which range from four to ten principles (SAMHSA, 
2011). For this thesis, one of the leading experts in trauma, and trauma-informed approaches, the Substance Abuse and Mental Health Services Administration (SAMSHA)'s six guiding principles have been selected to reference due to how the principles align with the unique needs of houseless youth. SAMHSA defines the six core principles of Trauma-informed Care as 1) safety 2) trustworthiness and transparency 3) peer support 4) collaboration and mutuality 5) empowerment, voice and choice, and 6) cultural, historical, and gender issues. Helping professionals who deliver TIC allow the six principles to guide all aspects of their work with houseless youth (SAMHSA, 2014).

\section{Background}

Trauma-informed Care as a service approach in youth-serving organizations began predominantly within "inpatient and juvenile mental health facilities," although it is practiced across many service settings including child welfare, juvenile justice, and substance abuse institutions (Hales, Kusmaul, \& Nochajski, 2017). The literature available on the topic of TIC in practice within houseless youth organizations suggests that the discussion is only in its infancy. The articles and readings yielded from the search demonstrate this, as only 4 out of the 17 readings were specific to TIC for houseless youth. Four readings were about TIC for maltreated youth, and nine readings were about Trauma-informed Care in general. Discourse communities that are involved in the conversation on TIC for houseless youth include the fields of social work, psychology, and children and youth services.

Much of the research accessed, painted a very general picture of Trauma-informed Care based on the approach's guiding core principles. There is some discrepancy over what the approach's core principles are, however, in each of the articles or readings that discussed the principles, three were frequently present. These were: 1) promoting safety of clients; 2) 
opportunity for choice and empowerment; and 3) establishing trust. Literature is especially limited regarding the effectiveness of the approach as no quantitative or qualitative data was located that measured the approach's efficacy with specifically houseless youth. One reason for this could be that Trauma-informed Care is not as much an established practice with houseless youth as it is with individuals who are accessing services for substance abuse and mental health issues, therefore, it will take time for this type of research to be conducted.

Due to the high rates of trauma among houseless youth, it is imperative that more research is performed regarding Trauma-informed Care in practice with these individuals to determine its effectiveness and also how it might best be practiced with this group. To be most effective, Trauma-informed Care must be tailored to houseless youth in meeting their unique needs, and it must evolve with the population as the population evolves (SAMHSA, 2014). In order to achieve this, research must be performed. Although this study did not examine the efficacy of Trauma-informed Care with houseless youth, it did find recurring themes and locate gaps within the literature that will better inform research and practice. In this paper, a narrative description and chart of the search process will be presented as well as themes that surfaced throughout the literature. Lastly, concluding thoughts will consist of an analysis of the results and further implications for practice.

\section{Reflexive Statement}

The topic of Trauma-informed Care as an approach to serve youth who are experiencing houselessness is a personal one for me. In my youth, I sought shelter in a variety of ways including couch surfing, staying overnight in my car, and sleeping on the street. My houseless situation prompted me to utilize services at emergency shelters that the rural town offered. The shelters I accessed did not operate from a trauma-informed lens. Perhaps if staff had been 
trained in how to deliver TIC, more of my long-term needs could have been addressed and met within those walls. However, my road to recovery and exiting houselessness required me to receive support from many more agencies.

To provide context for my pathway to houselessness, I find it necessary to share some of my history and upbringing. When I was six years old, my world as I knew it crumbled when my parents divorced. Myself, and my brother whom I idolized, were separated. My mother and I moved out of our family home and my brother stayed behind with my father. Eventually, after much family strain and ongoing contention between my parents, I completely severed all ties to my father and his side of the family. I even lost a relationship with my brother for nearly ten years even though we lived two miles apart in the same small town.

When I reached adolescence, I began experimenting with drugs and alcohol. Abusing substances became a way for me to cope with my unresolved emotional pain and loss of my family. It was a way for me to numb the traumatic stress symptoms and control the way I felt. It was an escape. Little did I know, my experimental phase would turn into addiction, cause me to experience severe mental health issues as a result of a drug-induced psychosis, cause me to become houseless and take me ten years to overcome. Throughout the years I struggled with addiction, I was treated by many helping professionals. I developed relationships with social workers, psychiatrists, drug and alcohol counselors, and emergency shelter staff to name a few. Ultimately, these relationships not only led me to choose a career path in social work, but they also gave me a valuable opportunity to observe helping services from the point of view of the service user. 
My hope is that my lived experience has benefitted me throughout this research process and will continue to fuel my passion for serving houseless youth throughout a career in social work. I want to acknowledge that my background and trauma history has strongly influenced my topic choice for my thesis, and the entire research process. I also find it important to recognize that at times reading about trauma and its negative impacts can be psychologically triggering. There were moments during the research process that I personally felt triggered by the reading, and found it helpful to set aside the project, and engage in self-care. I would also like to use this space to acknowledge the reader's trauma history and express my compassion for you and all that you have overcome.

\section{Methods}

4.1 Research question

The research process and thematic analysis was guided by the research question, 'How might Trauma-informed Care be practiced within houseless youth organizations?'

\subsection{Search strategy}

A search of the selected databases, PsycINFO, and Academic Search Premier was performed. Additionally, the grey literature database, Bielefeld Academic Search Engine (BASE) was searched for relevant readings to the topic. These databases were recommended by a PSU librarian due to their alignment with the topic of Trauma-informed Care for houseless youth as the databases contain articles and readings rooted in the social sciences, social work and human behavior. To further increase the breadth of the scope, publications were located and selected from a nationally recognized trauma-informed organization, the Substance Abuse and Mental Health Administration (SAMHSA), and a statewide trauma-informed organization, Trauma Informed Oregon (TIO). 
The following search terms were used during the search: Trauma-informed Care, traumainformed intervention, trauma-informed practice, homelessness, housing instability, homeless youth, homeless young people, homeless adolescents, houseless youth, houseless young people, houseless adolescents, inadequately housed youth, inadequately housed young people, and inadequately housed adolescents. Boolean search was used for all three databases, while search terms were altered for SAMHSA and Trauma Informed Oregon as Boolean search was not compatible with these websites. All articles and readings that resulted from the Boolean search were imported to the Mendeley reference management and research software.

\subsection{Eligibility criteria}

Articles and readings that were selected all had to be written within the years 1998 to 2019, and they consisted of journal articles, books, reports, policy statements, one thesis, and one editorial. The year 1998 was chosen as the beginning year as this is when the core principles of Trauma-informed Care were spread significantly after the "Women, Co-occurring Disorders and Violence Study" was performed (Wilson, Pence, \& Conradi, 2013). The study provided helping professionals with a trauma-informed framework to address the needs of women who were living with mental illness and substance abuse issues who had also experienced trauma (Wilson, Pence, \& Conradi 2013).

Additional inclusion criteria consisted of the following: 1) the reading was about youth (14-25) who were experiencing houselessness in the form of couch surfing, staying overnight in a vehicle, or on the streets, and who had trauma histories; 2) the reading provided information about trauma-informed practices for youth (14-25) in general with no specific social issue other than houselessness as the focus; 3 ) the reading provided examples of Trauma-informed Care within organizations and programs that serve houseless people or families (of any age) e.g. 
shelters, day centers, and outreach programs; 4) the reading was about Trauma-informed Care and its key elements without being specifically about any other social issue besides houselessness. Articles and readings that were excluded consisted of the following: 1) the reading was about trauma specific services such as therapies to treat PTSD and, 2) the reading was solely about the implementation of TIC into an organization without providing any information on the approach in practice with young people or more specifically, young houseless people.

\subsection{Screening process}

Of the articles and readings that were stored in the Mendeley reference and research software, a check for duplicates was run. Once duplicate articles and readings were located, the first stage of screening for relevant articles took place. Titles of all articles and readings were read and analyzed first, excluding those that had no relevance to the topic of TIC for houseless youth. Next, articles or readings that referred to TIC and houselessness, or Trauma-informed Care in general or specific to maltreated or houseless youth went through stage two of the screening process where abstracts were read to determine eligibility for the review. Those not relevant were excluded. The final stage of the screening process consisted of reading full-text articles of the most relevant articles and readings generated from the search.

\subsection{Data management}

Articles and readings that were selected for the final review were both stored in the Mendeley reference and research software as well as a word document, and then printed out in hard copy form. Readings were printed so that notes could be taken by hand directly on the source as it was read through, while additional notes were typed into a word document. A template was created with information that was pulled from two different scoping review article 
examples as to the type of findings scoping reviews present. The template consisted of prompts that were filled in for each article and reading. The note-taking template was as follows:

\author{
REPORT ON EVIDENCE (THAT ADDRESSES AND INFORMS PRACTICE): \\ METHODS USED (QUAL/QUANT/FRAMEWORKS): \\ KEY CONCEPTS/DEFINITIONS: \\ IDENTIFY CHARACTERISTICS OR FACTORS RELATED TO A CONCEPT: \\ IDENTIFY/ANALYSE GAPS: \\ NOTES:
}

4.6 Thematic analysis

Notes from the literature were reviewed several times in order to identify themes. During each read through, main concepts were located and assigned a particular color post-it. Grouping concepts by color allowed overarching concepts to be revealed as these concepts had the highest number of one particular color post-it attached to it. Four themes arose from the grouped concepts. Those themes were: establishing safety, importance of the helping relationship, challenging behaviors viewed as coping strategies, and gaps in research and practice. A list was made of all articles and readings that provided information regarding each theme. Articles and readings were then marked with which theme they contained, and relevant sections of the readings were highlighted for ease of reference.

\title{
5. Results
}

5.1 Search and selection 
The database and grey literature search generated 4,027 articles and readings relevant to the topic of TIC for houseless youth. After deduplication was performed, 2,149 records remained. During the screening process, 2,123 articles and readings were then excluded due to the title and abstract lacking relevance to the topic, which left 26 full-text articles to be read. After full-text articles were read and analyzed, nine were excluded due to having too much focus on a social issue other than youth houselessness, being a one page book review of a more informative article, or the article was no longer available which left 17 articles and readings that were included in the analysis.

5.2 Chart -PRISMA flow diagram of search and selection

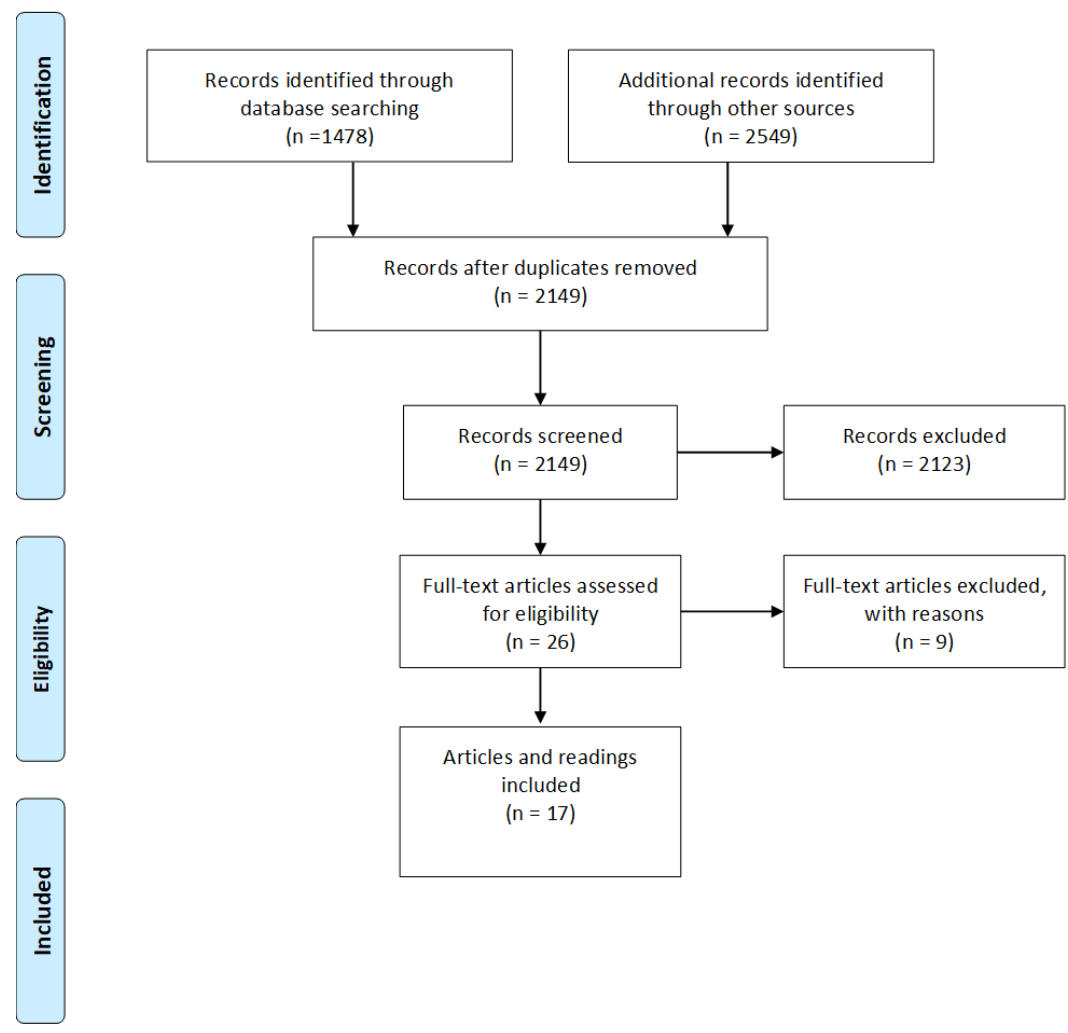

From: Moher D, Liberati A, Tetzlaff J, Altman DG, The PRISMA Group (2009). Preferred Reporting Items for Systematic Reviews and Meta-Analyses: The PRISMA Statement. PLoS Med 6(6): e1000097. doi:10.1371/journal.pmed1000097 
5.3 General characteristics of readings and articles

\begin{tabular}{|c|c|c|}
\hline \multicolumn{3}{|c|}{ Table 1: Characteristics of Readings and Articles $(n=17)$} \\
\hline Characteristic & Number $(n=17)$ & Percentage $(\%)$ \\
\hline Publication year & & \\
\hline $2008-2012$ & 4 & 23.5 \\
\hline $2014-2016$ & 6 & 35.3 \\
\hline $2017-2019$ & 7 & 41.2 \\
\hline Publication type & & \\
\hline Journal article & 6 & 35.3 \\
\hline Book & 3 & 17.6 \\
\hline Report & 2 & 11.8 \\
\hline Thesis dissertation & 1 & 5.9 \\
\hline Editorial & 1 & 5.9 \\
\hline Policy statement & 4 & 23.5 \\
\hline Sector & & \\
\hline Substance Abuse and & 3 & 17.6 \\
\hline Mental Health & & \\
\hline Social Work & 3 & 17.6 \\
\hline Children and Youth Services & 1 & 5.9 \\
\hline Human Services & 1 & 5.9 \\
\hline Psychology & 2 & 11.8 \\
\hline Clinical Psychology & 2 & 11.8 \\
\hline Mental Health & 1 & 5.9 \\
\hline Other & 4 & 23.5 \\
\hline Method/Framework & & \\
\hline Quantitative study & 3 & 17.6 \\
\hline Qualitative study & 1 & 5.9 \\
\hline SPECs model & 1 & 5.9 \\
\hline Biopsychosocial framework & 1 & 5.9 \\
\hline Resilience framework & 2 & 11.8 \\
\hline Strengths-based framework & 4 & 23.5 \\
\hline $\begin{array}{l}\text { Ecological developmental } \\
\text { perspective }\end{array}$ & 2 & 11.8 \\
\hline Other & 3 & 17.6 \\
\hline
\end{tabular}




\section{Theme 1: Establishing safety}

A houseless youth organization that is trauma-informed aims to help houseless youth feel safe (Lemm, 2016). A qualitative study that interviewed staff from a trauma-informed day center that serves houseless youth highlights the importance of positive first interactions between youth and staff, and how such interactions contribute to the establishment of safety (Lemm, 2016). A staff member explained,

Creating a positive environment is critical. These youth not only misunderstand their symptoms resulting in negative self-talk and low self-esteem, but many are hyper vigilant and are unable to feel safe in any situation. So many of these youth are isolated with limited supports or connections. Helping to create positive relationships and build community is critical in this regard.

For houseless youth accessing day centers or shelters, being greeted by a smiling staff member can make all the difference when it comes to their perception of safety (Levenson, 2017). A youth that perceives the houseless organization as welcoming and safe is much more likely to continue accessing services so that they may get further needs met (Lemm, 2016).

There are several practices a houseless youth organization can carry out to help youth feel safe in their environment while accessing services. It is recommended that there be good lighting throughout the establishment, proper maintenance of the building such as working locks, bathrooms and showers that function properly, and communal areas that are kept clean (Levenson, 2017). It is important that houseless youth organizations have proper accommodations for disabled youth such as bathrooms and showers that they can safely navigate, wheelchair accessible pathways, and functioning elevators (Levenson, 2017). In a 
houseless youth organization, agency staff must frequently assess the physical space for safety as well as encouraging youth feedback for how the space might continuously be made safer (SAMHSA, 2014). Youth suggestions for change must be taken seriously and implemented as promptly as possible (SAMHSA, 2014). This demonstrates to youth that their voices have been heard and what they say matters (SAMHSA, 2014). It is important to give youth who are experiencing houselessness as much opportunity to have "power and control over their own circumstances as possible" (Bath, 2008). One way this can be done is by ensuring that youth have control over their own belongings (Haskett, 2014). A houseless youth organization that provides locked spaces for youth to be able to keep their belongings, and to get into any time during the time they are accessing services can contribute to the establishment of safety (Haskett, 2014). Youth can be comforted knowing that their belongings will be safe where they left them and they will not be taken by another youth who is accessing services (Haskett, 2014). Lastly, having adequate security within the building and on the grounds may decrease the amount of conflicts that arise within the physical space, thus, increasing youth perception of safety (Levenson, 2017).

It is suggested that being cognizant of a houseless youth's trauma history is the first step to establishing a safe environment and a safe helping relationship (Levenson, 2017). To more fully contribute to establishing safety for youth within houseless youth organizations, staff must present themselves as safe. Among other attributes, transparency is an attribute that may lead to the establishment of safety for houseless youth. Steele \& Malchiodi give an example of a helping professional who practiced transparency with a youth they were engaging by saying,

Listen, you don't know me, you don't know anything about me, and you shouldn't trust me until you get to know me. So, I'm going to say a few things. After I leave, you will 
have a chance to think about whether or not you want to spend any time talking with me. Whatever you decide is final. It's your choice. You are in control.

In some cases, even if a helping professional has attributes that are consistent with a safe relationship such as transparency, honesty, and reliability, a youth may still be unable to deem that professional as a safe person. The way a helping professional speaks or carries themselves might remind the youth of someone that once hurt them, which could trigger a youth's survival response to kick in, causing further harm to them and hindering the progress of the therapeutic relationship. It is significant that the helping professional recognize when this is occurring and find another, less-triggering person for the youth to work with (Steele \& Malchiodi, 2012).

It is suggested that trauma-informed staff who use respectful language with youth, are mindful of youths' ability to choose which services they receive, and who practice cultural awareness contribute to youths' sense of safety. Person first language is recommended when engaging houseless youth such as referring to youth as "youth who are experiencing homelessness," rather than "homeless youth." The latter may attach stigmatizing labels to youth and could lead to the internalization of harmful self-perceptions that become a part of their identity. Additionally, before beginning an assessment with a youth who is experiencing houselessness, it is vital that a trauma-informed helping professional let the youth know that they may stop the discussion or activity at any time. Their request to stop must be promptly honored. Helping professionals who ask open-ended questions may help youth to feel safer as well as they are given the opportunity to share their unique experiences in their own words. Conversely, asking only "yes" or "no" questions may prompt youth to give answers that they think helping professionals want to hear (Steele \& Malchiodi, 2012). Lastly, it is suggested that a helping professional can contribute to a youth's perception of safety by being aware of cultural attitudes 
and practices that they may have, including cultural awareness throughout the agency's services (Haskett, 2014). For example, the physical space may have brochures or flyers offered in a variety of languages, and intake and assessment forms may be offered in a youth's native language. "A knowledge of culture" should be implemented into the houseless youth organization's policies and interventions as well to further increase a youth's sense of safety while receiving services (Haskett, 2014, p. 133).

In reference to Harris and Fallot's five guiding principles of Trauma-informed Care, much of the literature points to safety as being the foundational principle that must be established first, while the remaining four principles: trustworthiness, choice, collaboration, and empowerment build upon safety. However, a study that examined the dimensionality of Trauma-informed Care (Hales, Kusmaul, \& Nochajski, 2017) suggests that the core guiding principles of the approach don't make up a hierarchical system with safety as the base, but rather, that all five of Harris and Fallot's principles are "interrelated and equally important." Authors suggest that "development within any of the domains will lead toward the enhancement of others and that change initiatives and strategies need not give initial primacy to safety" (2017, p.323).

\section{Theme 2: Importance of the helping relationship}

As a result of significant, prolonged trauma, many houseless youth perceive helping professionals, or adults in general, as unsafe- which can pose a challenge to the development of the helping relationship. Unfortunately, many of these youth have also been further harmed while receiving services from helping professionals who place high demands on them and respond negatively when youth don't meet such demands (Haskett, 2014). These factors increase the level of difficulty for good-intentioned trauma-informed helping professionals who 
try to build connections with houseless youth (Haskett, 2014). In her thesis dissertation, Lemm (2016) discusses findings from research that suggest supportive relationships to be the greatest need among many houseless youth. Additionally, she found that youth were more likely to exercise resilience when they had positive supportive relationships. One way a trauma-informed helping professional may develop a helping relationship with a youth is to approach them from a nonjudgmental stance. A helping professional must recognize how challenging it is for houseless youth to form connections with adults and give them the appropriate time and space while they try to build trust (Lemm, 2016). A staff member from a day center that serves houseless youth, and a participant in a qualitative study, said in reference to building trust with youth, "I let them know that they can trust me over time and that it is their choice when they want to do that. And I feel that really helps create a different relationship, a different dynamic right of the bat" (Lemm, 2016, p.38).

Research suggests that the greatest protective factor for youth who have experienced childhood trauma is the relationship with an adult who is reliable, predictable, and responsive to their needs (Bartlett \& Steber, 2019). Perry (2009) suggests that caring relationships act as a buffer against the negative effects of trauma that many houseless youth experience. Positive relationships are said to "support neural networks" that involve becoming attached and attuned to others (Steele \& Malchiodi, 2012). Knowing this places the helping professional in a very valuable position where they can potentially form positive connections with houseless youth, which supports youths' ability to develop further positive relationships with others (Steele \& Malchiodi, 2012). In his article, The Three Pillars of Trauma-informed Care, (Bath, 2008) discusses a study that examined factors that led to positive outcomes in psychotherapy with 
youth. The study found that the helping relationships between youth and service provider “account for twice as much positive change” as therapy itself (Bath, 2008, p. 20).

Throughout the helping relationship, a helping professional has the opportunity to teach houseless youth many valuable skills. Because many houseless youth have not had parents or caregivers who have taught them how to effectively manage their emotions, helping professionals assume this role. Rather than adopting coercive methods when a youth becomes upset, trauma-informed helping professionals co-regulate with them, modeling appropriate responses to overstimulating situations or environments (Bath, 2008). Emotional regulation skills are said to be a crucial protective factor that aids healthy growth and development. Additionally, helping professionals who use active listening with youth, create opportunities for youth to practice self-reflection. Bath (2008) explains that a crucial part of the trauma recovery and healing process is a present, trusted adult with whom youth have the space to freely share their experiences. Lastly, the trauma-informed helping relationship serves as a platform that allows youth to re-frame negative perceptions they have of adults in helping positions, or adults in general. Positive interactions between the youth and the helping professional lead to the formation of positive associations of helping professionals, which can increase youths' level of comfortability and willingness to receive further services (Bath, 2008).

Four of the nine readings that discussed the importance of the helping relationship, elaborated on the fact that power differences should not exist between the youth and the helping professional (SAMHSA, 2014). A trauma-informed helping professional recognizes that traumatic experiences leave houseless youth feeling powerless (Clark, Classen, Fourt, \& Shetty, 2015). When youth are receiving trauma-informed services, they play an active role in their recovery process by being involved in treatment planning, which leads to empowerment (Clark, 
Classen, Fourt, \& Shetty, 2015). Levenson (2017) discusses the importance of creating a shared power dynamic between the client and the helping professional, where the professional contributes their learned knowledge, and the youth is considered the expert of their own life and story. In short, shared power leads to true healing (Levenson, 2017).

\section{Theme 3: Challenging behaviors viewed as coping strategies}

Lambert, Emerson, Horan, \& Naughton (2017) discuss the impact of trauma on the brain and behavior by explaining that youth who have experienced ongoing trauma "are at risk of excessive cortisol arousal, causing cell death in the hippocampus"(p. 2). This brain process that is activated by traumatic stress leads to a list of health and behavioral health issues including: difficulty forming and accessing memories, an increased startle response to stimuli in the youth's environment, making poor choices, and violent behavior (Lambert, Emerson, Horan, \& Naughton, 2017). SAMHSA (2011) reports, youth who have experienced trauma are more likely to engage in drug and alcohol and tobacco use than youth who have not experienced traumatic events. Additionally, SAMHSA (2011) reported that a higher number of traumatic events endured by youth correlated to higher rates of behavioral issues. For example, in a sample of 4,278 youth, $50 \%$ of youth who had experienced three or more traumatic events used "alcohol, tobacco, or marijuana in the previous six months (SAMHSA, 2011, p. 2). This compares to 39\% of youth who used "alcohol, tobacco, or marijuana and who had experienced 1-2 traumatic events $(2011$, p. 2). The challenging behaviors, or traumatic stress responses that houseless youth present increase barriers to receiving helping services and demonstrate the need for trauma-informed helping professionals who understand the impact of trauma on youth behavior. 
Houseless youth who actively avoid people and places that remind them of traumatic events they have experienced, or who have debilitating anxiety or depression as a result of trauma, may find it difficult to engage houseless youth organizations (Bartlett \& Steber, 2019). At times these youth can become aggressive or their behavior may be unpredictable if they are emotionally flooded by a psychological trigger in their environment (Bartlett \& Steber, 2019). Instead of meeting these behaviors that are often perceived by helping professionals as resistance or defiance, with judgment, a trauma-informed helping professional would meet the individual with compassion and understanding (Bartlett \& Steber, 2019). SAMHSA (2014) outlines the importance of viewing youths' challenging behaviors as coping strategies to difficult life circumstances. A trauma-informed helping professional realizes that presenting behaviors are traumatic stress symptoms of either previous or current trauma and strives to meet youth with compassion while they access the organization's services (SAMHSA, 2014).

There is discussion in the literature about the limited understanding of trauma and trauma symptoms being only conceptualized as single events that have a fixed set of symptoms, rather than recognizing the ongoing complex nature of trauma, and how trauma may be presented through behavior (Clark, Classen, Fourt, \& Shetty, 2015). Unlike the PTSD diagnosis that classifies trauma symptoms as hyperarousal (e.g., aggression, sleep disturbances, and trouble concentrating), negative mood or cognition changes, and avoidance of trauma reminders, a trauma-informed approach takes into account the complexity of trauma and how symptoms manifest in a variety of ways (Clark, Classen, Fourt, \& Shetty, 2015). Houseless youths' trauma symptoms can manifest through difficulties self-regulating their thoughts, behavior, and emotions which can result in behaviors such as self-harming, engaging in risky sex, and substance abuse. Houseless youth often practice these self-destructive behaviors in attempt to 
self-regulate (Clark, Classen, Fourt, \& Shetty, 2015). Furthermore, a trauma-informed helping professional understands that traumatic stress symptoms such as hypervigilance, estrangement from others, and avoidance may serve as self protection for youth who are inhabiting the streets and are vulnerable to further victimization (Mohr, Coates, \& Mcleod, 2012). Through a traumainformed lens, all of the behaviors and trauma responses listed are considered survival strategies for houseless youth to cope with their adverse situations (Clark, Classen, Fourt, \& Shetty, 2015).

\section{Theme 4: Gaps in research and practice}

Currently, interventions that are most used with houseless youth are interventions that focus primarily on crisis response and meeting youths' immediate needs, while teaching them job skills and providing education (Vitopoulos, Keilburger, Frederick, \& Mckenzie, 2017). There is only limited research regarding the efficacy of this type of intervention, and there is even less research available that discusses houseless youth organizations that utilize Trauma-informed Care to address the deeper needs youth have regarding their trauma histories. One study found that $24 \%$ of youth who had recently secured housing, lost their housing in only one year (Vitopoulos, Keilburger, Frederick, \& Mckenzie, 2017). The rest of the youth in the sample "experienced social isolation, complex trauma symptoms, and poor physical health" (2017, p. 501). This may point to the need for TIC to be implemented in houseless youth organizations so that more of youths' underlying trauma needs can be met, perhaps leading to more lasting positive change and housing stability. Vitopoulos, Keilburger, Frederick, \& Mckenzie (2017) explain that there is a demand for interventions that address mental health issues among houseless youth, as well as research that demonstrates the effectiveness of such interventions. 
Few articles and readings identified in the review provided specific examples of what TIC might look like in practice with houseless youth. Three of the eight readings that discussed establishing safety for youth within houseless youth organizations did provide specific examples of how to create a safe environment regarding the establishment's lighting, functionality, and cleanliness (Haskett, 2014). However, practice recommendations regarding other facets of practice such as developing a helping relationship with houseless youth and viewing youth's challenging behaviors as adaptive behaviors to adverse environments were abstract. There is a pressing need for research that provides specific practice examples of TIC in application with houseless youth so that some of the ambiguity about the implementation of the approach may be resolved (Trauma Informed Oregon, 2016).

Levenson (2017) explains that trauma-informed practices must involve an understanding of how social factors such as racial and gender inequality, and economic disparities impact individuals receiving services. Trauma histories that include experiences of classism, racism, or heterosexism must be acknowledged in order to more effectively address trauma as well as systemic barriers that many houseless youth face (Mohr, Coates, \& Mcleod, 2012). The literature regarding these topics is sparse. Four of the nine readings that highlighted gaps in research and practice discussed the need for research that focused on broader, structural components of houselessness (Mohr, Coates, \& Mcleod, 2012). For example, there is a lack of literature regarding disadvantaged people being at greater risk of enduring traumatic experiences based on their multiple social identities, and what TIC might look like in practice with these individuals (Mohr, Coates, \& Mcleod, 2012). Also lacking in the literature is how these individuals might navigate systems that could potentially lead to them exiting their houseless situations, while they face added barriers of systemic oppression (Bent-Goodley, 2018). The 
sixth principle of trauma informed care, "understanding cultural, historical, and gender issues" was only mentioned in four out of seven readings that discussed TIC's core guiding principles. This finding may demonstrate the lack of focus on social and cultural factors that impact houseless youths' trauma experiences and ability to exit houselessness.

\section{Discussion}

This scoping review examined literature available on the topics of Trauma-informed Care and houseless youth to determine how the approach might be practiced within houseless youth organizations. Interestingly, none of the 17 articles and readings located for this review were specifically about trauma-informed practice techniques with houseless youth. Therefore, relevant sections that discussed practice examples were drawn out of the readings. This review provides a compilation of both specific and abstract practice examples that were found in the literature to better inform research and practice. Additionally, much of the literature regarding Trauma-informed Care did not readily report current gaps in research and practice. Therefore, a closer examination and analysis of the literature was required so that this review could present the gaps that are negatively impacting the care houseless youth are receiving.

Findings from this review suggest that the guiding core principles that stem from Harris and Fallot's original five principle theory are used and adapted in a variety of ways to accommodate service users across settings (Hales, Kusmaul, \& Nochajski, 2017). I found that, out of the different combinations of principles named throughout the literature, SAMHSA's six guiding principles are most tailored to houseless youth in meeting their unique trauma needs. This is because the sixth guiding principle allows helping professionals to recognize the importance of including cultural, historical and gender issues into the understanding of trauma, 
and into care and treatment (SAMHSA, 2014). These are issues that significantly impact houseless youth. Additionally, findings demonstrate that the most discussed guiding principle throughout the literature is safety. This may place an added emphasis on the importance of helping professionals assisting youth in establishing safety first before any other principles of Trauma-informed Care can be carried out. However, I found that the study performed by Hales, Kusmaul, \& Nochajski (2017) suggests that safety is not necessarily the most important principle to be established first, and that organizations that practice Trauma-informed Care could essentially use any of the core principles as the foundation of their work with houseless youth.

\section{Practice Implications}

Findings from this review could assist houseless youth organizations that are considering implementing TIC in their agency. For those at the implementation phase, the findings may provide a greater overall understanding of the approach and useful examples of how traumainformed helping professionals may begin to apply the approach's principles to their work with houseless youth. Additionally, findings may clear up confusion helping agencies have about TIC's core guiding principles, and which principles they might use to structure their work with houseless youth. Further aiding the implementation process is findings from the study performed by Hales, Kusmaul, \& Nochajski (2017) that suggests any one of the core guiding principles may be used as the foundation guiding the approach. However, it might be wise for any agency that is implementing the approach to further examine this claim, as much of the literature places emphasis on the importance of establishing safety first before further needs of houseless youth are met. 
Much of the findings suggest that delivering TIC to houseless youth can lead to the successful development and maintenance of helping relationships between youth and the helping professional. These positive relationships could lead to positive outcomes among both staff and youth receiving services. Trauma-informed helping professionals who address youth's deeper trauma needs may experience increased job satisfaction as their work may allow them to have more meaningful experiences with the youth they serve. Perhaps increased job satisfaction among helping professionals could lead to further positive interactions with youth receiving services with the process acting as a positive feedback loop.

This review is limited due to a lack of available research on Trauma-informed Care specifically in application with houseless youth. Because the concept of Trauma-informed Care to serve houseless youth is in its infancy, much of the articles and readings located for the review were nonspecific to houseless youth and were about TIC in general, or maltreated, traumatized youth in general. Research specific to TIC and houseless youth is needed to generate more results that will inform practice with this group of people. It is then that more specific practice examples may surface. Additionally, there were no studies located for this review that measured the efficacy of the approach. Therefore, the effectiveness of the approach is only demonstrated in this review by verbal evidence among helping professionals.

\section{Conclusion}

This scoping review examined available literature on the topic of Trauma-informed Care and houseless youth to determine how the approach might be practiced within houseless youth organizations. Although specific and abstract practice examples were pulled from the literature, it is evident that future research on this topic should include more detailed examples regarding how the approach is carried out in service to houseless youth. This type of research would 
decrease ambiguity surrounding how the approach is practiced leading to helping professionals who are better informed. Once TIC becomes clearer and more established in houseless youth organizations, research measuring the approach's efficacy is necessary to determine its real value in serving houseless youth.

\section{References}

Bartlett, J. D., \& Steber, K. (2019). How to implement trauma-informed care to build resilience to childhood trauma. In Child Trends. Retrieved from https://www.childtrends.org/publications/how-to-implement-trauma-informed-care-tobuild-resilience-to-childhood-trauma

Bath, H. (2008). The three pillars of trauma-informed care. Reclaiming Children and Youth, 17(3).

Bent-Goodley, T. B. (2019). The necessity of trauma-informed practice in contemporary social work. National Association of Social Workers, 64(1), 5-7.

Clark, C., Classen, C. C., Fourt, A., \& Shetty, M. (2015). Treating the trauma survivor: An essential guide to trauma-informed care. Routledge/Taylor \& Francis Group.

Davies, B. R., \& Allen, N. B. (2017). Trauma and homelessness in youth: Psychopathology and intervention. Clinical Psychology Review, 54.

Hales, T., Kusmaul, N., \& Nochajski, T. (2017). Exploring the dimensionality of traumainformed care: Implications for theory and practice. Human Services Organizations: Management, Leadership and Governance, 41(3).

Haskett, Mary E., et al. Supporting families experiencing homelessness current practices, and future directions. ebook ed., New York, Springer, 2014. 
Lambert, S., Gill-Emerson, G., Horan, A. and Naughton, A. (2017) Moving Towards Trauma Informed Care. A model of research and practice, Cork: Cork Simon Community. http://www.corksimon.ie/aces-at-cork-simon/

Lemm, K. (2016). Working in the gray: An urban drop-in center utilizing trauma-informed care with youth experiencing homelessness (Master's thesis).

Levenson, J. (2017). Trauma-informed social work practice. National Association of Social Workers, 62(2), 105-113.

Mohr, S. M., Coates, J., \& Mcleod, H. (2012). Responding to the needs of youth who are homeless: Calling for politicized trauma-informed intervention. Children and Youth Services Review, 34, 136-143.

Perry, B. (2009). Examining child maltreatment through a neurodevelopmental lens: Clinical applications of the neurosequential model of therapeutics. Journal of Loss and Trauma, 14(4).

Peters, M., Godfrey, C. M., Khalil, H., McInerney, P., Parker, D., \& Soares, C. B. (2015). Guidance for conducting systematic scoping reviews. International Journal of EvidenceBased Healthcare, 13.

Pham, M. T., Rajic, A., Greig, J. D., Sargeant, J. M., Papadopoulos, A., \& McEwen, S. A. (2014). A scoping review of scoping reviews: Advancing the approach and enhancing the consistency. Research Synthesis Methods, 5.

Steele, W., \& Malchiodi, C. A. (2012). Trauma-informed practices with children and adolescents. New York, NY: Taylor and Francis Group.

Substance Abuse and Mental Health Administration. (2011). Helping children and youth who have experienced traumatic events. Retrieved from 
https://store.samhsa.gov/product/Helping-Children-and-Youth-Who-Have-ExperiencedTraumatic-Events/SMA11-4642

Substance Abuse and Mental Health Administration. (2014). SAMHSA's concept of trauma and guidance for a trauma-informed approach. Retrieved from https://store.samhsa.gov/product/SAMHSA-s-Concept-of-Trauma-and-Guidance-for-aTrauma-Informed-Approach/SMA14-4884.html

Trauma Informed Oregon. (2016). What is trauma informed care? Retrieved from http://traumainformedoregon.org/wp-content/uploads/2016/01/What-is-TraumaInformed-Care.pdf

Trauma Informed Oregon. (2018). Standards of practice for trauma informed care. Retrieved from https://traumainformedoregon.org/wp-content/uploads/2018/08/Guidelines-andStandards-of-Practice-for-Trauma-Informed-Care_March-2018.pdf

Vitopoulos, N., Keilburger, L. C., Frederick, T. J., Mckenzie, K., \& Kidd, S. (2017). Developing a trauma-informed mental health group intervention for youth transitioning from homelessness. American Psychological Association, 48(6). 